\title{
ANALISIS KEKAMBUHAN ORANG DENGAN SKIZOFRENIA MENGGUNAKAN METODE PARTIAL LEAST SQUARE STRUCTURAL EQUATION MODEL
}

\author{
Ira Indriyanti ${ }^{1 \S}$, G.K. Gandhiadi ${ }^{2}$, Made Susilawati ${ }^{3}$ \\ ${ }^{1}$ Program Studi Matematika, Fakultas MIPA - Universitas Udayana [Email: ira.indri19@gmail.com ] \\ ${ }^{2}$ Program Studi Matematika, Fakultas MIPA - Universitas Udayana [Email: gandhiadi@unud.ac.id] \\ ${ }^{3}$ Program Studi Matematika, Fakultas MIPA - Universitas Udayana [Email: mdsusilawati@unud.ac.id ] \\ ${ }^{\S}$ Corresponding Author
}

\begin{abstract}
Schizophrenia is a psychotic disorder characterized by major disorders in the mind and emotions. People with schizophrenia (ODS) can experience recurrence if they do not receive proper care. The latent variable used in this study was ODS reccurence. One method that can determine the relationship between latent variables and latent variables with the indicator is the partial least square structural equation model (PLS-SEM). This study was conducted to see how the structural model of ODS recurrence data and to know the factors that most influence ODS recurrence. The results of this study concluded that the resulting model was good enough with a large $R$-square value of 0.8577 , but not all variables used in this study had a significant effect on ODS recurrence. ODS recurrence is significantly influenced by family support and community social support variables. While medication compliance and physician control regularity will not have a significant effect without family support. The worse treatment of families and communities around ODS recurrence will occur more often.
\end{abstract}

Keywords: Community social support, Family Support, ODS recurrence, PLS-SEM

\section{PENDAHULUAN}

Kesehatan pada manusia dikategorikan menjadi dua yaitu kesehatan fisik dan kesehatan jiwa. Kesehatan jiwa merupakan kondisi sehat secara emosional dan psikologis dimana kondisi ini dapat dilihat dari hubungan komunikasi dengan orang lain yang efektif, kemampuan mengatasi masalah, dan kestabilan emosional (Videbeck, 2011). Terganggunya kesehatan jiwa menyebabkan adanya gangguan jiwa. Terdapat dua jenis gangguan jiwa yaitu gangguan jiwa berat dan gangguan jiwa ringan. Salah satu gangguan jiwa berat yang banyak terjadi di Indonesia adalah skizofrenia. Skizofrenia merupakan gangguan psikotik dengan gangguan utama dalam pikiran, emosi, dan perilaku. Orang dengan skizofrenia (ODS) biasanya masuk kedalam dunia fantasinya sendiri sehingga ODS cenderung menarik diri dari orang lain dan kenyataan, (Davison, et al., 2014).

Berdasarkan riset kesehatan dasar pada tahun 2013, jumlah ODS di Indonesia adalah 1,7 kejadian per 1000 penduduk dan Bali termasuk peringkat ketiga wilayah di Indonesia dengan gangguan jiwa berat. Data yang terungkap dari Renungan Kesehatan Mental di Bali tahun 2015, sebanyak 9.000 orang di Bali mengalami skizofrenia dan 350 orang di antaranya mengalami pemasungan.

Provinsi Bali hanya memiliki satu rumah sakit jiwa yaitu Rumah Sakit Jiwa Provinsi Bali (RSJ Bangli) yang terletak di kabupaten Bangli. RSJ Bangli hanya menerapkan pemberian perawatan selama enam bulan dikarenakan tidak memungkinkan untuk merawat pasien seumur hidup. Setelah pasien dibawa pulang oleh pihak keluarga akan sulit untuk me-ngontrol kesembuhan pasien dikarenakan kurang terbukanya keluarga terhadap keadaan pasien. Kekambuhan (relapse) pasca perawatan sering terjadi apabila ODS tidak mendapat perawatan dengan baik. Gejala dari kekam-buhan ODS yaitu menjadi ragu-ragu serta takut, tidak nafsu makan, sukar berkonsentrasi, sulit tidur, depresi dan menarik diri, serta raptus atau mengamuk (Yosep, 2009).

Terdapat beberapa faktor yang mempengaruhi kekambuhan pada ODS seperti kepatuhan dalam mengonsumsi obat, dukungan 
keluarga, keteraturan kontrol ke dokter, dan dukungan sosial masyarakat (Widodo, 2003). Berdasarkan data rawat inap RSJ Bangli, 90\% dari ODS yang sudah pernah dirawat inap akan dirawat inap kembali karena mengalami kekambuhan. Kekambuhan pada ODS dapat memicu penderita untuk melakukan upaya bunuh diri sehingga diperlukan penanganan yang baik agar dapat menurunkan risiko kekambuhan pada ODS.

Kekambuhan ODS merupakan sesuatu yang tidak dapat diukur secara langsung. Dalam statistika hal tersebut dinamakan variabel laten. Salah satu metode yang dapat menentukan hubungan antar variabel laten dengan variabel laten lainnya dan variabel laten dengan indikatornya adalah partial least square (PLS). Penelitian tentang ODS dan penelitian menggunakan PLS sebelumnya pernah dilakukan oleh Riawati (2011) yang menduga waktu sintasan ODS terhadap kekambuhan namun penelitian tersebut hanya menggunakan faktor internal dari diri ODS tanpa memperhatikan faktor lain yang dapat menyebabkan kekambuhan seperti faktor dukungan keluarga, keteraturan kontrol dokter, dan dukungan masyarakat. Berdasarkan hal tersebut penulis tertarik untuk mengadakan penelitian dengan judul "Analisis Kekambuhan Orang Dengan Skizofrenia Menggunakan Metode Partial Least Square".

\section{METODE PENELITIAN}

Penelitian ini dilakukan di Rumah Sakit Jiwa Provinsi Bali, Bangli dan Rumah Berdaya Denpasar dengan pertimbangan bahwa kedua tempat tersebut merupakan tempat bagi para ODS baik untuk berkarya, diterapi, dan diobati dari penyakitnya. Populasi dari penelitian ini adalah seluruh ODS, keluarga, dokter atau perawat atau terapis, serta masyarakat sekitar ODS yang ada di provinsi Bali. Sampel dalam penelitian ini adalah ODS, keluarga, dokter atau perawat atau terapis, serta masyarakat sekitar ODS yang ada di RSJ Bangli dan Rumah Berdaya Denpasar. Sebanyak 50 responden digunakan sebagai sampel dalam penelitian ini dengan pertimbangan bahwa dalam penelitian ini data sulit untuk di-dapatkan. PLS dapat digunakan untuk menge-neralisasi estimasi walaupun dengan sampel yang sangat kecil (30 observasi bahkan lebih kecil) maka 50 responden sudah dianggap cukup dalam proses analisis ini (Hair, et al., 2010). Sampel dalam penelitian ini merupakan data primer yang diperoleh menggunakan teknik purposive sampling. Sampel yang digu-nakan dalam penelitian diambil berdasarkan pertimbangan bahwa responden merupakan ODS, keluarga dari ODS, dokter atau perawat yang ada disekitar ODS, serta masyarakat yang ada disekitar ODS di tempat pengambilan sampel.

Variabel yang digunakan dalam penelitian ini yaitu kekambuhan ODS $\left(Y_{1}\right)$, kepatuhan mengonsumsi obat $\left(X_{1}\right)$; dukungan keluarga $\left(X_{2}\right)$, keteraturan kontrol dokter $\left(X_{3}\right)$; dan dukungan sosial masyarakat $\left(X_{4}\right)$. Penelitian ini dilakukan dengan bantuan instrumen penelitian berupa kuesioner sebagai alat ukur penyebab ter-jadinya kekambuhan maka perlu dilakukan uji validitas dan reliabilitas pada kuesioner untuk menguji kelayakan kuesioner yang digunakan.

Uji validitas bertujuan untuk menguji valid tidaknya jawaban kuesioner yang telah diberikan oleh responden. Pengukuran validitas dapat dilakukan dengan memperhatikan nilai corrected item-total correlation. Uji reliabilitas digunakan untuk mengukur konsistensi dari suatu instrumen. Pengukuran reliabilitas dapat dilakukan dengan memperhatikan nilai cronbach alpha.

Langkah-langkah yang dilakukan dalam penelitian ini yaitu:

\section{Mengkonstruksi diagram jalur}

Mengonstruksi diagram jalur bertujuan untuk menjelaskan bentuk hubungan antara variabel laten satu dengan variabel laten lainnya dan variabel laten dengan indikator-indikatornya.

2. Mengonversi diagram jalur ke sistem persamaan

\section{a. Outer Model}

Outer model adalah hubungan antara variabel laten dengan indikatornya dimana outer model mendefinisikan karakteristik konstruk dengan indikatornya.

\section{b. Inner Model}

Inner model menggambarkan hubungan antara variabel laten satu dengan lainnya berdasarkan hipotesis. Model persamaannya dapat dituliskan sebagai berikut:

$$
\eta=\beta_{\eta}+\Gamma_{\xi}+\varsigma
$$

dengan $\eta$ mewakili vektor variabel laten endogen (dependen), $\xi$ mewakili vektor variabel laten eksogen (independen), dan $\varsigma$ mewakili vektor sisaan.

\section{Mengestimasi parameter}

Metode kuadrat terkecil (least square methods) adalah pendugaan parameter yang 
digunakan dalam PLS. pendugaan dilakukan dengan proses pengulangan (iterasi) yang berhenti ketika sudah mencapai kondisi konvergen. Besarnya variabel laten dipengaruhi oleh indikator penyusunnya dapat dilihat pada outer loading untuk indikator bersifat reflektif dan outer weight untuk indikator bersifat formatif dari output yang dihasilkan oleh software SmartPLS, sedangkan besar pengaruh antar variabel laten dapat dilihat pada besar path coefficients dari output software SmartPLS.

\section{Goodness of Fit (GoF)}

Uji kecocokan model pada model struktural bertujuan untuk mengetahui seberapa besar penjelasan yang dapat digambarkan oleh model struktural.

a. Outer model

GoF model pada outer model dapat dilihat berdasarkan convergent validity dan discriminant validity (Jaya \& Sumertajaya, 2008). Discriminant validity digunakan dengan memperhatikan nilai square root of average extracted (AVE)

$$
A V E=\frac{\sum \lambda_{i}^{2}}{\sum \lambda_{i}^{2}+\sum \operatorname{var}\left(\varepsilon_{i}\right)}
$$

\section{b. Inner model}

GoF pada inner model diukur dengan memperhatikan $R$-square variabel laten endogen dengan interpretasi yang sama dengan analisis regresi.

\section{Pengujian hipotesis}

Pengujian hipotesis dilakukan dengan metode resampling boostrap. Statistik $t$ atau uji $t$ adalah statistik uji yang digunakan. Adapun hipotesis yang digunakan dalam penelitian ini adalah:

a. Pengaruh kepatuhan mengonsumsi obat terhadap kekambuhan ODS

$H_{0}$ : Kepatuhan mengonsumsi obat tidak mempengaruhi kekambuhan ODS

$H_{1}$ : Kepatuhan mengonsumsi obat mempengaruhi kekambuhan ODS

b. Pengaruh dukungan keluarga terhadap kekambuhan ODS

$H_{0}$ : Dukungan keluarga tidak mempengaruhi kekambuhan ODS

$H_{1}$ : Dukungan keluarga mempengaruhi kekambuhan ODS c. Pengaruh keteraturan kontrol doker terhadap kekambuhan ODS

$H_{0}$ : Keteraturan kontrol doker tidak mempengaruhi kekambuhan ODS

$H_{1}$ : Keteraturan kontrol doker mempengaruhi kekambuhan ODS

d. Pengaruh dukungan sosial masyarakat terhadap kekambuhan ODS

$H_{0}$ : Dukungan sosial masyarakat tidak mempengaruhi kekambuhan ODS

$H_{1}$ : Dukungan sosial masyarakat mempengaruhi kekambuhan ODS

Dengan kriteria pengujian $H_{0}$ ditolak ketika statistic $t>\mathrm{t}$ 224tati. Metode resampling memungkinkan adanya data berdistribusi be-bas, tanpa asumsi kenormalan, serta tidak memerlukan sampel yang besar. Pengujian dilakukan menggunakan statistic t, apabila diperoleh statistik $\mathrm{t} \geq$ t-tabel (alfa 5\%), maka hasil tersebut signifikan dan sebaliknya.

\section{HASIL DAN PEMBAHASAN}

\subsection{Karakteristik Reponden}

Karakteristik responden dalam penelitian ini meliputi: umur, gender, jenjang pendidikan, pekerjaan, status perkawinan, dan hubungan dengan ODS. Adapun hasil kuesioner tersebut diperoleh dalam bentuk Tabel yang menggambarkan karakteristik dari responden, antara lain:

Tabel 1. Karakteristik Responden

\begin{tabular}{|c|c|c|c|c|c|c|}
\hline & \multicolumn{4}{|c|}{ Hubungan dengan ODS } & \multirow[b]{2}{*}{ 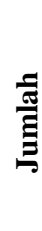 } \\
\hline & & $\tilde{0}$ & 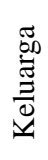 & 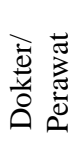 & 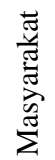 & \\
\hline \multirow{4}{*}{ 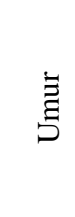 } & $21-30$ & 4 & 8 & 10 & 8 & 30 \\
\hline & $31-40$ & 10 & 2 & 0 & 3 & 15 \\
\hline & $41-50$ & 3 & 0 & 0 & 0 & 3 \\
\hline & $>50$ & 2 & 0 & 0 & 0 & 2 \\
\hline \multicolumn{2}{|c|}{ Jumlah } & 19 & 10 & 10 & 11 & 50 \\
\hline \multirow{2}{*}{$\begin{array}{l}\overline{0} \\
\overline{0} \\
\overline{0}\end{array}$} & Laki-laki & 12 & 7 & 6 & 5 & 30 \\
\hline & Perempuan & 7 & 3 & 4 & 6 & 20 \\
\hline \multicolumn{2}{|c|}{ Jumlah } & 19 & 10 & 10 & 11 & 50 \\
\hline
\end{tabular}


Tabel 1. Karakteristik Responden (Lanjutan)

\begin{tabular}{|c|c|c|c|c|c|c|}
\hline & \multicolumn{4}{|c|}{ Hubungan dengan ODS } & \multirow[b]{2}{*}{ 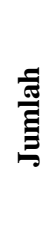 } \\
\hline & & $\tilde{0}$ & 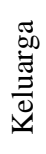 & 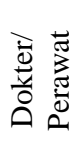 & 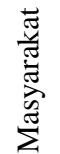 & \\
\hline \multirow{4}{*}{ 矛䔍 } & SMP & 3 & 0 & 0 & 0 & 3 \\
\hline & SMA & 15 & 8 & 1 & 5 & 29 \\
\hline & Sarjana & 1 & 2 & 8 & 6 & 17 \\
\hline & Pascasarjana & 0 & 0 & 1 & 0 & 1 \\
\hline \multicolumn{2}{|c|}{ Jumlah } & 19 & 10 & 10 & 11 & 50 \\
\hline \multirow{5}{*}{ 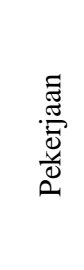 } & ASN & 1 & 0 & 10 & 0 & 11 \\
\hline & Karyawan & 0 & 0 & 0 & 2 & 2 \\
\hline & Wirausaha & 14 & 8 & 0 & 2 & 24 \\
\hline & Mahasiswa & 1 & 2 & 0 & 6 & 9 \\
\hline & Tidak Bekerja & 3 & 0 & 0 & 1 & 4 \\
\hline \multicolumn{2}{|c|}{ Jumlah } & 19 & 10 & 10 & 11 & 50 \\
\hline \multirow{2}{*}{ 总 } & Belum Kawin & 10 & 4 & 10 & 9 & 33 \\
\hline & Kawin & 9 & 6 & 0 & 2 & 17 \\
\hline \multicolumn{2}{|c|}{ Jumlah } & 19 & 10 & 10 & 11 & 50 \\
\hline
\end{tabular}

Sumber: Data Primer (2019), diolah

Pada Tabel 1. mengambarkan responden dari kalangan ODS yang berjenis kelamin laki-laki lebih besar daripada responden perem-puan. Hal ini sesuai dengan teori Adamo (2007) menyebutkan bahwa laki-laki memiliki kecenderungan menunjukan risiko tinggi mengalami skizofrenia sebab laki-laki cenderung memiliki produksi hormon stres yang berlebihan.

\subsection{Kelayakan Instrumen Penelitian}

Pada pengujian validitas dan reliabilitas ini dilakukan untuk masing-masing dimensi. Pengujian validitas dan reliabilitas instrumen penelitian ini menggunakan 30 data sebelum disebarkan kepada responden sebenarnya. Hasil pengujian validitas instrumen penelitian ini menunjukan bahwa semua pernyataan yang digunakan telah valid karena nilai corrected item-total correlation untuk semua variabel lebih besar dari 0,3 . Hasil pengujian reliabelitas juga menunjukkan bahwa intrumen penelitian telah reliabel karena nilai cronbach alpha lebih besar dari 0,6.

\subsection{Analisis Model Pengukuran}

Model pengukuran menampilkan hubu-ngan antara variabel laten dan indikator. Terdapat tiga tahap analisis, yaitu:

\section{Convergent Validity}

Pada tahap ini terdapat dua hal yang dilakukan, yaitu memerhatikan nilai outer loading dan nilai AVE. Nilai outer loading menunjukan kesamaan indikator dalam me-refleksikan suatu variabel laten.

a. Variabel Kepatuhan Mengonsumsi Obat $\left(X_{1}\right)$

Tabel 2. Nilai Outer Loading dan AVE Variabel

Kepatuhan Mengonsusi Obat

\begin{tabular}{|c|c|c|c|}
\hline $\begin{array}{l}\text { Variabel } \\
\text { laten }\end{array}$ & Indikator & $\begin{array}{l}\text { Outer } \\
\text { Loading }\end{array}$ & AVE \\
\hline \multirow{6}{*}{ 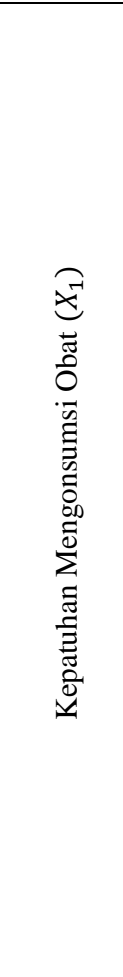 } & $\begin{array}{l}\text { ODS tidak merasa } \\
\text { jenuh atau bosan } \\
\text { minum obat }\left(\mathrm{x}_{11}\right)\end{array}$ & 0,6504 & \multirow{6}{*}{$\begin{array}{l}\text { g) } \\
\text { ह } \\
0\end{array}$} \\
\hline & $\begin{array}{l}\text { ODS beranggapan } \\
\text { bahwa penyakitnya } \\
\text { belum sembuh sehi- } \\
\text { ngga perlu minum } \\
\text { obat }\left(\mathrm{x}_{12}\right)\end{array}$ & 0,9063 & \\
\hline & $\begin{array}{l}\text { Tangan ODS tidak } \\
\text { sering gemetaran } \\
\text { (tremor) setelah mi- } \\
\text { num obat }\left(x_{13}\right)\end{array}$ & 0,6910 & \\
\hline & $\begin{array}{l}\text { ODS selalu memi- } \\
\text { num obat secara te- } \\
\text { ratur tanpa diingat- } \\
\text { kan oleh keluarga } \\
\left(\mathrm{x}_{14}\right)\end{array}$ & 0,5979 & \\
\hline & $\begin{array}{l}\text { ODS selalu memi- } \\
\text { num obat sesuai } \\
\text { dengan dosis yang } \\
\text { di berikan dari kli- } \\
\text { nik atau rumah sa- } \\
\text { kit }\left(\mathrm{x}_{15}\right)\end{array}$ & 0,5986 & \\
\hline & $\begin{array}{l}\text { ODS tidak meng- } \\
\text { hentikan obat yang } \\
\text { dikonsumsi sebe- } \\
\text { lum waktunya }\left(\mathrm{x}_{16}\right)\end{array}$ & 0,7884 & \\
\hline
\end{tabular}

Sumber: Data Primer 2019, (diolah)

Berdasarkan Tabel 2. dapat dilihat bahwa ter-dapat empat variabel dengan nilai outer loading kurang dari 0,7. Hair, et al. (2014) menjelaskan bahwa apabila nilai outer loading kurang dari 0,4 indikator reflektif harus dihilangkan. Sementara apabila nilai outer loading berada pada interval 0,4 sampai 0,7 $(0,4 \leq$ outer loading $\leq 0,7)$ maka penghapusan in-dikator dilakukan dengan memper-hatikan nilai AVE, artinya penghapusan indikator akan dilakukan ketika nilai AVE tidak memenuhi nilai yang diharapkan $(A V E \geq 0,5)$ apabila eliminasi indikator menyebab nilai AVE meningkat, maka indikator tersebut harus 
dihilangkan, namun ketika eliminasi faktor tidak meningkatkan nilai AVE maka indikator tersebut dapat di pertahankan. Berdasarkan Tabel 4.2 terlihat nilai AVE pada variabel ini adalah 0,5099. Hal ini berarti sudah melebihi nilai yang diharapkan sehingga eliminasi indikator pada variabel ini tidak diperlukan.

b. Variabel Dukungan Keluarga $\left(X_{2}\right)$

Tabel 3. Nilai Outer Loading dan AVE Variabel Dukungan Keluarga

\begin{tabular}{|c|c|c|c|}
\hline $\begin{array}{c}\text { Variabel } \\
\text { laten }\end{array}$ & Indikator & $\begin{array}{l}\text { Outer } \\
\text { Loading }\end{array}$ & AVE \\
\hline \multirow{6}{*}{ 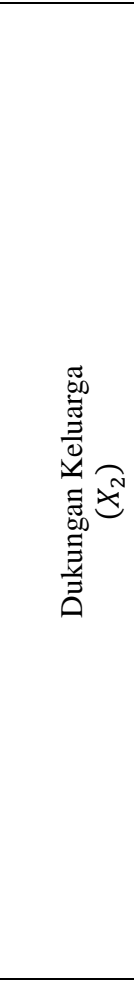 } & $\begin{array}{l}\text { Keluarga meng- } \\
\text { anggap bahwa ski- } \\
\text { zofrenia adalah pe- } \\
\text { nyakit yang tidak } \\
\text { memalukan }\left(x_{21}\right)\end{array}$ & 0,6013 & \multirow{6}{*}{$\frac{\infty}{2}$} \\
\hline & $\begin{array}{l}\text { Selalu mengajak } \\
\text { ODS berkomuni- } \\
\text { kasi }\left(x_{22}\right)\end{array}$ & 0,8114 & \\
\hline & $\begin{array}{l}\text { Memberikan pujian } \\
\text { pada ODS saat } \\
\text { membantu menger- } \\
\text { jakan pekerjaan ru- } \\
\text { mah }\left(x_{23}\right)\end{array}$ & 0,7978 & \\
\hline & $\begin{array}{l}\text { Mendukung kegi- } \\
\text { atan yang dilaku- } \\
\text { kan ODS selama } \\
\text { bersifat positif }\left(x_{24}\right)\end{array}$ & 0,6349 & \\
\hline & $\begin{array}{l}\text { Keluarga perduli } \\
\text { dengan keadaan } \\
\text { ODS dan tidak } \\
\text { membiarkannya } \\
\left(x_{25}\right)\end{array}$ & 0,8632 & \\
\hline & $\begin{array}{l}\text { Keluarga selalu } \\
\text { mengajak ODS } \\
\text { untuk berobat me- } \\
\text { lakukan jadwal } \\
\text { kon-trol ulang }\left(x_{26}\right)\end{array}$ & 0,6499 & \\
\hline
\end{tabular}

Sumber: Data Primer (2019), diolah

Pada Tabel 3. terlihat bahwa indikator $x_{21}, x_{24}$, dan $x_{26}$ memiliki outer loading kurang dari 0,7. Indikator pada variabel dukungan keluarga tidak ada yang dihilangkan dengan pertimbangan bahwa nilai AVE pada variabel ini adalah 0,5378 yang telah melebihi 0,5 .

\section{c. Variabel Keteraturan Kontrol Dokter $\left(X_{3}\right)$}

Pada Tabel 4. terlihat bahwa indikator $x_{33}$ memiliki outer loading kurang dari 0,7. Indikator pada variabel keteraturan kontrol dokter tidak ada yang dihilangkan dengan pertimbangan bahwa nilai AVE pada variabel ini adalah 0,5502 yang telah melebihi 0,5.
Tabel 4. Nilai Outer Loading dan AVE Variabel Keteraturan Kontrol Dokter

\begin{tabular}{|c|c|c|c|}
\hline \begin{tabular}{|l|} 
Variabel \\
laten
\end{tabular} & $\begin{array}{l}\text { Keterangan } \\
\text { Indikator }\end{array}$ & $\begin{array}{l}\text { Outer } \\
\text { Loading }\end{array}$ & AVE \\
\hline \multirow{4}{*}{ 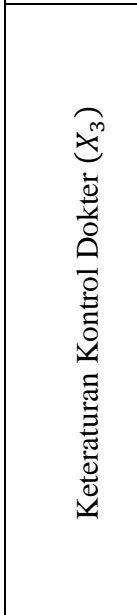 } & $\begin{array}{l}\text { ODS tidak malas } \\
\text { kontrol karena ti- } \\
\text { dak memiliki ken- } \\
\text { daraan }\left(x_{31}\right)\end{array}$ & 0,8467 & \multirow{4}{*}{$\begin{array}{l}0 \\
\delta \\
n \\
n \\
0\end{array}$} \\
\hline & $\begin{array}{l}\text { ODS tidak malas } \\
\text { kontrol ulang ke ru- } \\
\text { mah sakit walau- } \\
\text { pun jenuh menung- } \\
\text { gu antrian berobat } \\
\left(x_{32}\right)\end{array}$ & 0,7738 & \\
\hline & $\begin{array}{l}\text { ODS menjalani te- } \\
\text { rapi atas kesada- } \\
\text { rannya ingin sem- } \\
\text { buh }\left(x_{33}\right)\end{array}$ & 0,5456 & \\
\hline & $\begin{array}{l}\text { ODS harus kontrol } \\
\text { tepat waktu agar } \\
\text { cepat sembuh }\left(x_{34}\right)\end{array}$ & 0,7664 & \\
\hline
\end{tabular}

Sumber: Data Primer (2019), diolah

d. Variabel Dukungan Sosial Masyarakat $\left(X_{4}\right)$

Tabel 5. Nilai Outer Loading dan AVE Variabel Dukungan Sosial Masyarakat

\begin{tabular}{|c|c|c|c|}
\hline $\begin{array}{l}\text { Variabel } \\
\text { laten }\end{array}$ & $\begin{array}{l}\text { Keterangan } \\
\text { Indikator }\end{array}$ & $\begin{array}{l}\text { Outer } \\
\text { Loading }\end{array}$ & AVE \\
\hline \multirow{4}{*}{ 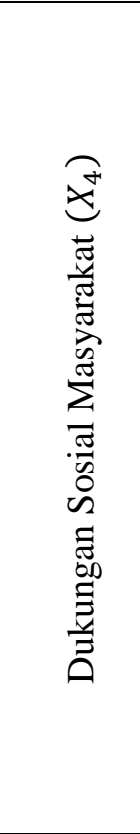 } & $\begin{array}{l}\text { Masyarakat seki- } \\
\text { tar ODS meneri- } \\
\text { ma keberadaan- } \\
\text { nya dengan baik } \\
\left(x_{41}\right)\end{array}$ & 0,7130 & \multirow{4}{*}{$\frac{\bar{\sigma}}{\tilde{n}}$} \\
\hline & $\begin{array}{l}\text { ODS yang baru } \\
\text { keluar dari Ru- } \\
\text { mah Sakit Jiwa } \\
\text { tidak kesulitan } \\
\text { mendapat peker- } \\
\text { jaan }\left(x_{42}\right)\end{array}$ & 0,6365 & \\
\hline & $\begin{array}{l}\text { Masyarakat seki- } \\
\text { tar mengikut ser- } \\
\text { takan ODS dalam } \\
\text { kegiatan sosial } \\
\left(x_{43}\right)\end{array}$ & 0,8398 & \\
\hline & $\begin{array}{l}\text { Lingkungan tem- } \\
\text { pat tinggal ODS } \\
\text { tidak mengucil- } \\
\text { kannya karena } \\
\text { tahu penyakitnya }\end{array}$ & 0,6704 & \\
\hline
\end{tabular}

Sumber: Data Primer (2019), diolah

Pada Tabel 5. terlihat bahwa indikator $x_{33}$ dan $x_{34}$ memiliki outer loading kurang dari 0,7. Indikator pada variabel dukungan sosial masyarakat tidak ada yang dihilangkan dengan pertimbangan bahwa nilai AVE pada variabel ini adalah 0,5171 sudah melebihi nilai yang diharapkan 0,5. 
e. Variabel Kekambuhan ODS ( $Y$ )

Tabel 6. Nilai Outer Loading dan AVE Variabel Kekambuhan ODS

\begin{tabular}{|c|c|c|c|}
\hline $\begin{array}{c}\text { Variabel } \\
\text { laten }\end{array}$ & $\begin{array}{l}\text { Keterangan } \\
\text { Indikator }\end{array}$ & $\begin{array}{l}\text { Outer } \\
\text { Loading }\end{array}$ & AVE \\
\hline \multirow{6}{*}{ 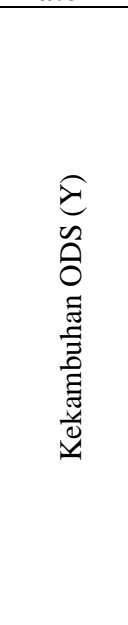 } & $\begin{array}{l}\text { ODS tidak ragu-ragu } \\
\text { maupun takut }\left(y_{1}\right)\end{array}$ & 0,6783 & \multirow{6}{*}{$\frac{\sqrt{n}}{\stackrel{a}{0}}$} \\
\hline & $\begin{array}{l}\text { ODS memiliki nafsu } \\
\text { makan yang baik } \\
\left(y_{2}\right)\end{array}$ & 0,8490 & \\
\hline & $\begin{array}{l}\text { ODS dapat berkon- } \\
\text { sentrasi dengan baik } \\
\left(y_{3}\right)\end{array}$ & 0,9096 & \\
\hline & $\begin{array}{l}\text { ODS tidak sulit tidur } \\
\left(y_{4}\right)\end{array}$ & 0,8469 & \\
\hline & $\begin{array}{l}\text { ODS tidak menga- } \\
\text { lami depresi dan me- } \\
\text { narik diri }\left(y_{5}\right)\end{array}$ & 0,8643 & \\
\hline & $\begin{array}{l}\text { ODS tidak menga- } \\
\text { lami raptus (menga- } \\
\text { muk tanpa sebab) } \\
\left(y_{6}\right)\end{array}$ & 0,9372 & \\
\hline
\end{tabular}

Sumber: Data Primer (2019), diolah

Pada Tabel 6. terlihat bahwa indikator $y_{1}$ memiliki outer loading kurang dari 0,7. Indikator pada variabel kekambuhan ODS tidak ada yang dihilangkan dengan pertimbangan bahwa nilai AVE pada variabel ini adalah 0,7251 sudah melebihi nilai yang diharapkan 0,5 .

\section{Discriminant Validity}

Discriminant validity merupakan suatu tahap yang menyiratkan bahwa setiap variabel laten adalah variabel yang unik, artinya variabel itu tidak diwakili oleh variabel lain dalam suatu model (Hair, et al., 2014). Hasil analisis terhadap nilai cross loading ditampilkan pada Tabel 7.

Tabel 7. Nilai Cross Loading

\begin{tabular}{|c|c|c|c|c|c|}
\hline & 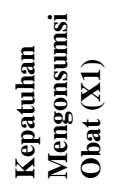 & 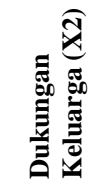 & 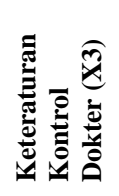 & 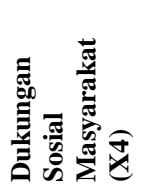 & 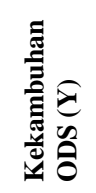 \\
\hline $\mathrm{x} 11$ & 0,6504 & 0,3412 & 0,2435 & 0,4846 & 0,4647 \\
\hline $\mathrm{x} 12$ & 0,9063 & 0,8640 & 0,5863 & 0,6616 & 0,7921 \\
\hline $\mathrm{x} 13$ & 0,6910 & 0,5620 & 0,4984 & 0,4645 & 0,5059 \\
\hline $\mathrm{x} 14$ & 0,5979 & 0,3708 & 0,1932 & 0,3126 & 0,4249 \\
\hline $\mathrm{X} 15$ & 0,5986 & 0,5264 & 0,4408 & 0,4372 & 0,5426 \\
\hline $\mathrm{x} 16$ & 0,7884 & 0,6600 & 0,6521 & 0,5601 & 0,6271 \\
\hline $\mathrm{x} 21$ & 0,4156 & 0,6013 & 0,4937 & 0,4120 & 0,5479 \\
\hline $\mathrm{x} 22$ & 0,6815 & 0,8114 & 0,3833 & 0,5679 & 0,6442 \\
\hline
\end{tabular}

Tabel 7. Nilai Cross Loading (Lanjutan)

\begin{tabular}{|c|c|c|c|c|c|}
\hline & 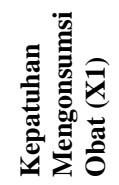 & 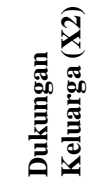 & 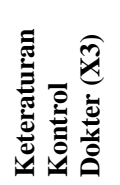 & 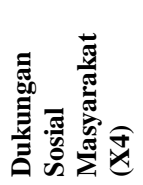 & 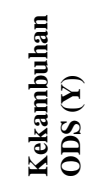 \\
\hline x23 & 0,7927 & 0,7978 & 0,6150 & 0,5366 & 0,6498 \\
\hline $\mathrm{x} 24$ & 0,4029 & 0,6349 & 0,4569 & 0,4536 & 0,5692 \\
\hline $\mathrm{x} 25$ & 0,6396 & 0,8632 & 0,6282 & 0,6020 & 0,7128 \\
\hline $\mathrm{x} 26$ & 0,5978 & 0,6499 & 0,5718 & 0,4973 & 0,5651 \\
\hline $\mathrm{X} 31$ & 0,3700 & 0,5434 & 0,8467 & 0,6535 & 0,6433 \\
\hline $\mathrm{x} 32$ & 0,4334 & 0,4821 & 0,7738 & 0,6046 & 0,6358 \\
\hline $\mathrm{x} 33$ & 0,4824 & 0,4392 & 0,5456 & 0,2705 & 0,3093 \\
\hline $\mathrm{x} 34$ & 0,6738 & 0,6761 & 0,7664 & 0,5168 & 0,5798 \\
\hline $\mathrm{x} 41$ & 0,4781 & 0,4166 & 0,4347 & 0,7130 & 0,5273 \\
\hline $\mathrm{x} 42$ & 0,3641 & 0,2210 & 0,5276 & 0,6365 & 0,4835 \\
\hline $\mathrm{x} 43$ & 0,6222 & 0,7598 & 0,6555 & 0,8398 & 0,8386 \\
\hline \begin{tabular}{|l|}
$\mathrm{x} 44$ \\
\end{tabular} & 0,5057 & 0,4956 & 0,4148 & 0,6704 & 0,5050 \\
\hline $\mathrm{y} 1$ & 0,4655 & 0,6174 & 0,5418 & 0,5701 & 0,6783 \\
\hline y2 & 0,7459 & 0,7168 & 0,6853 & 0,7323 & 0,8490 \\
\hline $\mathrm{y} 3$ & 0,7257 & 0,7797 & 0,6842 & 0,7572 & 0,9096 \\
\hline $\mathrm{y} 4$ & 0,6732 & 0,7230 & 0,6408 & 0,7243 & 0,8469 \\
\hline y5 & 0,7753 & 0,7060 & 0,5687 & 0,7602 & 0,8643 \\
\hline y6 & 0,6942 & 0,7562 & 0,7372 & 0,7854 & 0,9372 \\
\hline
\end{tabular}

Sumber: Data Primer (2019), diolah

Berdasarkan Tabel 7. dapat dilihat bahwa nilai cross loading suatu variabel terhadap indikatornya lebih tinggi dibandingkan indikator pada variabel lainnya. Hal ini menjelaskan bahwa variabel laten dapat memprediksi indikatornya lebih baik dibandingkan dengan indikator pada variabel lainnya.

\section{Composite Reliability}

Composite reliability adalah tahap analisis pada model pengukuran yang memberikan perkiraan keandalan berdasarkan korelasi indikator yang digunakan. Hair, et al.(2014) menyatakan bahwa nilai composite reliability lebih dari 0,7 dianggap memuaskan sedangkan nilai composite reliability 0,6 sampai 0,7 dikatakan masih dapat diterima. Adapun hasil analisis pada tahap ini berdasarkan output smartPLS dapat dilihat pada Tabel 8.

Tabel 8. Nilai Composite Reliability

\begin{tabular}{|l|l|l|}
\hline Varibel Laten & $\begin{array}{l}\text { Composite } \\
\text { Reliability }\end{array}$ & Keterangan \\
\hline $\begin{array}{l}\text { Kepatuhan } \\
\text { mengonsumsi obat }\end{array}$ & 0,8590 & Baik \\
\hline Dukungan keluarga & 0,8726 & Baik \\
\hline $\begin{array}{l}\text { Keteraturan kontrol } \\
\text { dokter }\end{array}$ & 0,8089 & Baik \\
\hline $\begin{array}{l}\text { Dukungan sosial } \\
\text { masyarakat }\end{array}$ & 0,8270 & Baik \\
\hline Kekambuhan ODS & 0,9400 & Baik \\
\hline
\end{tabular}

Sumber: Data Primer (2019), diolah 
Pada Tabel 8. terlihat bahwa nilai composite reliability dari setiap variabel laten lebih dari 0,7 . Hal ini berarti, dapat diartikan model pengukuran pada penelitian ini baik dan dapat dipercaya keandalannya.

\subsection{Analisis Model Struktural}

Analisis model struktural bertujuan untuk melihat kemampuan prediksi model dan hubungan antara variabel laten satu dengan variabel laten lainnya. Ukuran paling umum untuk mengoreksi model struktural adalah $R^{2}$ yang mewakili efek gabungan antar variabel eksogen pada variabel endogen. Hasil analisis $R^{2}$ terlihat pada Tabel 9 .

Tabel 9. Nilai $R^{2}$ Variabel Kekambuhan ODS

\begin{tabular}{|c|c|c|}
\hline Variabel Laten & R Square & $\begin{array}{c}\text { R Square } \\
\text { Adjusted }\end{array}$ \\
\hline Kekambuhan ODS & 0,8577 & 0,8451 \\
\hline
\end{tabular}

Sumber: Data Primer (2019), diolah

Pada Tabel 9. terlihat bahwa nilai $R^{2}$ pada kekambuhan ODS sebesar 0,8577, sehingga dapat dikatakan bahwa kepatuhan mengonsumsi obat, dukungan keluarga, keteraturan kontrol dokter, dan dukungan sosial masyarakat memiliki efek yang besar terhadap kekambuhan ODS.

\subsection{Hasil Analisis PLS dan Pengujian Hipotesis}

Pengujian hipotesis bertujuan untuk mengetahui faktor yang signifikan mempengaruhi kekambuhan ODS dengan menggunakan metode resampling boostrap. Hasil pengujian dengan boostraping dapat dilihat pada Tabel 10. dan Gamber 1. berikut:

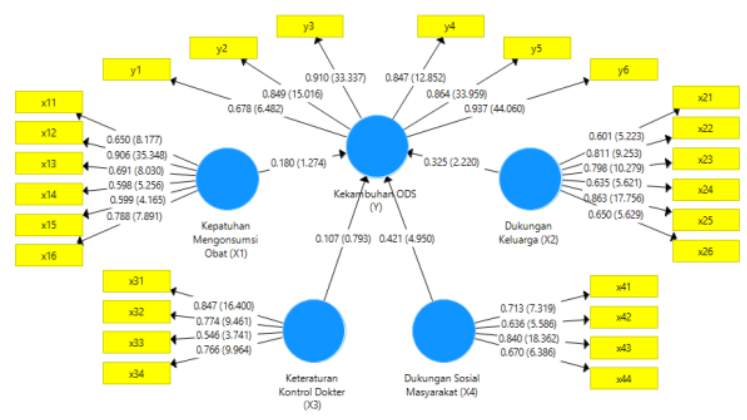

Gambar 1. Hasil Pengujian dengan Boostraping Kasus Kekambuhan ODS
Tabel 10. Hasil Pengujian dengan Boostraping Kasus Kekambuhan ODS

\begin{tabular}{|l|l|l|}
\hline \multicolumn{1}{|c|}{ Variabel laten eksogen } & \multicolumn{1}{|c|}{$\begin{array}{c}\text { Koefisien } \\
\text { Jalur }\end{array}$} & $\begin{array}{c}\boldsymbol{T} \\
\text { statistics }\end{array}$ \\
\hline $\begin{array}{l}\text { Kepatuhan Mengonsumsi } \\
\text { Obat (X1) -> Kekambuhan } \\
\text { ODS (Y) }\end{array}$ & 0,180 & 1,2742 \\
\hline $\begin{array}{l}\text { Dukungan Keluarga (X2) -> } \\
\text { Kekambuhan ODS (Y) }\end{array}$ & 0,325 & 2,2203 \\
\hline $\begin{array}{l}\text { Keteraturan Kontrol Dokter } \\
\text { (X3) -> Kekambuhan ODS } \\
\text { (Y) } 0,107\end{array}$ & 0,7925 \\
\hline $\begin{array}{l}\text { Dukungan Sosial Masyarakat } \\
\text { (X4) -> Kekambuhan ODS } \\
(Y)\end{array}$ & 0,421 & 4,9501 \\
\hline
\end{tabular}

Sumber: Data Primer (2019), diolah

Menurut koefisien-koefisien parameter jalur yang diperoleh pada Gambar 1. dan Tabel 10. maka dapat dibentuk model persamaan struktural sebagai berikut:

$$
Y=0,18 X_{1}+0,325 X_{2}+0,107 X_{3}+0,421 X_{4}+\varsigma
$$

Berdasarkan pada Gambar 1. dan Tabel 10. diperoleh hasil pengujian hipotesis dengan metode boostraping dengan $\mathrm{t}$ tabel sebesar 1,6794 adalah:

1. Kepatuhan mengonsumsi obat mempengaruhi kekambuhan ODS

Hubungan antara variabel kepatuhan mengonsumsi obat dengan kekambuhan ODS memiliki nilai statistik t sebesar 1,2742 dengan nilai koefisien jalur sebesar 0,180. Hal ini berarti tidak terdapat bukti yang cukup untuk menolak $H_{0}$ sehingga dapat dikatakan bahwa kepatuhan mengonsumsi obat tidak berpangaruh signifikan terhadap kekambuhan ODS.

2. Dukungan keluarga mempengaruhi kekambuhan ODS

Hubungan antara variabel dukungan keluarga dengan kekambuhan ODS memiliki nilai statistik t sebesar 2,2203 dengan nilai koefisien jalur sebesar 0,325. Hal ini berarti $H_{0}$ ditolak sehingga dikatakan bahwa dukungan keluarga berpengaruh signifikan terhadap ke-kambuhan ODS.

3. Keteraturan kontrol dokter mempengaruhi kekambuhan ODS

Hubungan antara variabel keteraturan kontrol dokter dengan kekambuhan ODS memiliki nilai statistik t sebesar 0,7925 dengan nilai koefisien jalur sebesar 0,107. Hal ini berarti tidak terdapat bukti yang cukup untuk menolak $H_{0}$ sehingga dapat dikatakan bahwa keteraturan kontrol dokter tidak berpangruh signifikan terhadap kekambuhan ODS. 
4. Dukungan sosial masyarakat mempengaruhi kekambuhan ODS

Hubungan antara variabel dukungan sosial masyarakat dengan kekambuhan ODS memiliki nilai statistik $\mathrm{t}$ sebesar 4,9501 dengan nilai koefisien jalur sebesar 0,421. Hal ini berarti $H_{0}$ ditolak sehingga dikatakan bahwa dukungan sosial masyakat berpengaruh signifikan terhadap kekambuhan ODS.

Relapse dapat terjadi pada pasien yang tidak mendapatkan dukungan dari keluarga, dan hanya menyerahkan pasien ke rumah sakit dan diberi obat-obatan anti psikotik. Hal ini berarti bahwa kepatuhan ODS mengonsumsi obat dan keteraturan ODS kontrol dokter dipengaruhi oleh dukungan keluarga ODS sehingga pemberian obat dan keteraturan kontrol tidak akan berpengaruh secara signifikan tanpa adanya dukungan dari keluarga. Sehingga secara langsung dapat dikatakan bahwa adanya dukungan sosial dapat menurunkan risiko timbulnya gejala-gejala terjadinya kekambuhan (Sefrina et al., 2016).

\section{KESIMPULAN}

Berdasarkan hasil penelitian terkait kekambuhan ODS dengan menggunakan PLSSEM dapat disimpulkan bahwa model yang dihasilkan sudah cukup baik dengan nilai $R$ square yang cukup besar yaitu 0,8577. model yang diperoleh adalah:

$Y=0,18 X_{1}+0,325 X_{2}+0,107 X_{3}+0,421 X_{4}+\varsigma$

Kekambuhan ODS dipengaruhi secara signifikan oleh variabel dukungan keluarga dan dukungan sosial masyarakat Sedangkan kepatuhan mengonsumsi obat dan keteraturan kontrol dokter tidak akan berpengaruh secara signifikan tanpa adanya dukungan dari keluarga.

\section{DAFTAR PUSTAKA}

Adamo, P. J. (2007). The Genotype Diet. Jakarta: PT Gramedia Pusaka Utama.
Davidson, G.C., Neale, J.M., \& King, A.M. (2012). Abnormal Psychology, 12th ed. Berkeley: John WIley and Sons Inc.

Ghozali, I. (2011). Structural Equation Modeling Metode Alternatif dengan Partial Least Square. Semarang: Badan Penerbit Undip.

Hair, J. J., Hult, G.M., Ringle, C. M. \& Sa rstedt, M. (2014). A Primer On Partial Least Square Equation Modeling (PLS-SEM). Los Angeles: SAGE.

Hair, J.F., Anderson, R.E., Tatham, R.L., \& Black, W.C. (2010). Multivariate Data Analysis with Reading Seventh Edition. New Jersey: Prentice-Hall, Inc.

Jaya, I.G.N.M. \& Sumertajaya, I.M. (2008). Pemodelan Persamaan Struktural Dengan Partial Least Square. Semnas Matematika dan Pendidikan Matematika , 1,pp.118-32.

Riawati, N. M. (2011). Analisis Sintasan Pasien Skizofrenia Terhadap Kekambuhan (Relapse) Dengan Pendekatan Regresi Cox. Skripsi. Bukit Jimbaran: Jurusan Matematika, Fakultas Matematika dan Ilmu Pengetahuan Alam, Universitas Udayana.

Sefrina, F. \& Latipun. (2016). Hubungan Dukungan Keluarga dan Keberfungsian Sosial Pada Pasian Skizofrenia Rawat Jalan. Jurnal Ilmiah Psikologi Terapan, Vol. 04, No. 02, 140-160.

Videbeck, S. L. (2011). Psychiatric Mental Health Nursing. 5th Edition. Wolters Kluwer Health. Lippincott William \& WIlkins.

Widodo, A. (2003). Buku Ajar Keperawatan Jiwa I. Surakarta: Universitas Muhammadiyah Surakarta.

Yosep, I. (2009). Keperawatan Jiwa. Bandung: PT. Refika Aditama. 